\title{
The Restrictive Factors and the Solution for the Development of Community Commerce_-Take Yanta District as an Example
}

\author{
Guanhua Dong ${ }^{1, a}$, Jie Shang ${ }^{2, b}$,
}

${ }^{1}$ Xi'an University, NO1,Keji six Road, Yanta District of Xi'an, China,710065

${ }^{2}$ Xi'an University, NO1,Keji six Road, Yanta District of Xi'an, China,710065

a258332239@qq.com, b432818455@qq.com

Keywords: Community; Community commerce; Enterprise; Community development.

\begin{abstract}
Community commerce is important for urban commercial space, and it is also an important part of modern service industry. There are several problems on community business development in Yanta district, such as low level of product differentiation, the consumer demand cannot be satisfied, community safety can not be guaranteed and so on. Community commercial enterprises should be taken to improve the level of product differentiation, the introduction of $\mathrm{O} 2 \mathrm{O}$ management mode and other measures to enhance the quality of service; community should establish service window and platform, by strengthening cooperation with good reputation for the enterprise community business development escort..
\end{abstract}

\section{社区商业发展的制约因素及其解决路径一以西安市雁塔区为例}

\author{
董冠华1, a, 商洁2,b, \\ 1 西安文理学院经济管理学院, 雁塔, 西安, 陕西, 中国 \\ 2西安文理学院经济管理学院, 雁塔, 西安, 陕西, 中国 \\ a258332239@qq.com, b432818455@qq.com
}

关键词：社区；社区商业; 企业; 社区发展

中文摘要. 社区商业是城市商业空间的一个重要层次, 也是现代服务业的重要组成部分。雁 塔区社区商业发展中存在产品差异化程度低、难以满足居民消费需求、社区安全难以保障等 问题。社区商业企业应该采取提高产品差异化程度，引入 $\mathrm{O} 2 \mathrm{O}$ 经营模式等措施来提升服务品 质; 社区应该建立服务窗口和平台, 通过加强与信誉度好的企业合作为社区商业发展保驾护 航。

\section{1. 引言}

社区商业是城市社会经济发展到一定阶段的产物。近年来，随着我国经济的快速发展， 城市化进程的不断加快和人民生活水平的提高，社区商业的发展越来越受到广泛关注，已经 成为一项关乎社会和谐、环境宜居、社会保障重要的民生工程。我国城市商业建设进程主要 经历了城市中心商业, 区域中心商业集中建设的发展阶段，但城市社区商业还是和城市商业 发展状况和整体市场发展水平不相符。城市的社区商业建设已经成为我国城市商业发展结构、 完善社区服务功能和谐组合的发展软肋。 


\section{2. 社区商业概述}

\section{1 社区}

社区是若干社会群体或社会组织聚集在某一个领域里所形成的一个生活上相互关联的大 集体, 是社会有机体最基本的内容。按照社区形成方式划分, 可分为自然社区和法定社区。 按照社区功能来划分, 可以将社区分为: 专能社区和综合社区。按照社区地理环境来划分, 可以把社区分为平原社区、山区社区、高原社区和海滨社区等; 按照社区的发展模式来划分, 可以把社区分为大型社区、中型社区、小型社区和微型社区等; 按照社区发展水平来划分, 可以将社区分为传统社区、发展中社区、现代社区或发达社区。

\section{2 社区商业}

社区商业最早于 20 世纪50年代出现于美国。国外的社区商业主要表现类型则主要以购物 中心的形式出现。购物中心是一个由零售商店及其相应设施组成的商店群, 一般都拥有宽敞 的地上地下停车场, 位置一般靠近繁荣的公路主干道, 便于顾客购物, 逐渐成为一种现代的 零售方式和社区发展的模式。目前, 我国社区商业主要表现形式主要是以在历史上就已经形 成的沿街商铺为载体, 大多通过零售的经营方式, 从事社区内的商业经营活动, 由于缺乏统 一规划, 业态档次均处于较低水平, 且社区商业功能不够健全。随着房地产业的发展, 特别 是商业房地产的逐渐成熟，社区商业发展得到了巨大的支持，取得了不小的进步，国内出现 了一大批 “购物中心”、“生活广场”、“娱乐休闲一条街” 等众多社区商业项目，向为社 区居民提供更高端和优质的服务的方向发展。

\section{3. 西安市雁塔区社区商业发展现状与问题}

\section{1 西安市雁塔区社区商业发展现状}

目前, 雁塔区社区商圈主要分布在雁塔区的中西部等率先发展起来的区域, 南门、小雁 塔、南稍门商圈相互交错, 形成较为有规模的商圈集合。而小寨商圈、吉祥村商圈、大雁塔 商圈等则相对独立, 没有形成相互交错, 相互影响的大型商圈。而新兴的曲江新区的商圈分 布独立且商圈数量少。整体来看, 雁塔区社区商圈分布呈现为区域内东西分布差异大, 商圈 数量和规模各地区都存在较大的差距。雁塔区社区商业类型分布主要以休闲娱乐为主, 达到 了总量的近三分之一。其次是餐饮服务、超市百货、企业。而医疗服务、银行服务、教育机 构的数量都相对较少。整体来看, 目前雁塔区社区商业的主要类型是小型分散式零售模式, 还没有形成大型集中式供销的方式。

\section{2 西安市雁塔区社区商业发展存在的问题}

\subsection{1 产品差异化程度低, 难以满足社区居民消费需求}

目前社区商业的类型主要有8类，餐饮服务占比较大，医疗、教育、休闲娱乐等占比较低， 难以满足社区的不同需求。且提供的产品和服务的同质性过强, 选择的余地小, 经营的主要 形态小商品经营, 难以形成大规模的经营模式。只能满足社区居民日常生活的最基本需求, 难以满足社区群众更高的大型购物需求。当居民想要购买大量的商品时, 居民更宁愿选择更 远, 商业类型更多, 商品更丰富的区域进行购买。而由于大量客源的流逝, 社区商业类型更 新的动力不足，进一步制约了社区商业的发展，产品的差异化程度难以提高。

\subsection{2 社区商业化程度加强, 影响社区居民生活环境}

社区是居民日常生活的地方, 在这里他们希望的得到的是舒适, 安逸, 便利的生活环境。 而商业的进驻, 势必会带来繁华与嘈杂。社区居民一方面希望商业进驻社区, 为他们带来更 加丰富的产品和服务, 让他们的生活更加便利; 另一方面, 社区居民又不希望社区商业的发 展打破他们舒适，安逸的生活环境。成为了制约社区商业的发展的一大因素。 


\subsection{3 商业企业进驻社区，社区安全保障难以满足}

社区商业的发展离不开商业企业对社区的进驻，而企业的发展离不开消费者，企业的不 断壮大, 顾客的范围会越来越广, 数量会越来越多。发展社区商业, 随之而来的是社区的人 员构成会逐渐变得复杂, 社区事务也会越来越多, 不仅给社区的管理增加难度, 而且会让社 区居民的居住安全感降低, 影响社区的居住的舒适感和幸福感。

\subsection{4 产品差异化程度低, 难以满足社区居民消费需求}

社区商业的发展是伴随经济的不断发展，社区的不断壮大而发展起来的。而在一个新社 区刚刚建设的时候，难以考虑到后期社区商业发展的需求和规划造成了在后期一些企业在入 驻的时候，侵占了社区的居住区或绿化区，造成了社区的不合理布局，影响了社区居民的生 活秩序。尤其是一些比较老的社区, 在社区规划方面则更为落后, 没有意识到社区的一些规 划布局的出发点是便民和利民。造成了商业企业的进驻，不仅没有给社区居民带来更多的便 利，而是更多的不方便和正常秩序受到影响的局面。

\section{4. 西安市雁塔区社区商业发展问题的解决路径}

\section{1 企业在社区商业发展中的转变}

4.1.1提高产品差异化程度，丰富产品消费类型

社区商业经济，作为我国市场经济发展的必然形式与成果之一，在满足社区居民需要的 同时, 需要在开展品牌化战略的基础上, 积极地鼓励各种经济形式做出不同的创新尝试, 完 善特色服务客户定制, 由于居民商业需求的多样性, 对各种商品与服务的需求有更加精确的 衡量，居民的商业需求从被动接受，向积极主动与量化确定的定制服务发展。

4.1.2引入O2O的经营模式, 拓宽社区商业发展渠道

随着网络及智能手机的日益普及,我国网民数量尤其是移动网民数量呈爆炸式增长，且逐 步向高年龄段扩散。这就给大型社区利用移动互联网发展商业创造了契机的同时也奠定了深 厚顾客基础。社区商业是一种强调区域性的商业模式，对于 $\mathrm{O} 2 \mathrm{O}$ 电子商务的模式具有天然的 适应性。对社区商家来说, $\mathrm{O} 2 \mathrm{O}$ 模式要求消费者利用互联网支付, 商家可以直观的通过客户 购买信息了解消费者的购物信息，为商家收集消费者购买数据提供了渠道，进而使商家能够 更好的了解消费者需求, 从而达成精准营销的目的, 更好地维护并拓展新客户。对社区居民 来说, $\mathrm{O} 2 \mathrm{O}$ 电子商务经营模式, 可以购买到品种丰富、内容更加全面的产品, 成功篎选并订购 符合自身需求的商品或服务。

4.1.3便民利民诚信经营, 积极参与社区服务和建设

社区中的企业，不能仅仅以盈利为目的。还要充分做到便民利民，在提供商品和其他服 务时, 要竭力以社区居民的真正需求为经营活动的出发点, 最大限度的提供社区居民真正需 要的商品和服务。同时, 社区商业企业, 还必须积极参加社区的建设和社区服务。只有积极 参与, 才能在日常生活中深入了解到社区居民最为真实的想法, 了解到他们最真实的需求和 对社区商业发展的期望。

\section{2 社区在社区商业发展中的转变}

4.2.1建立服务窗口和平台，让产品和服务直接面向社区居民

社区、居民和企业是构成社区商业的三大要素。社区在社区商业发展中的作用不可小觑。 作为社区商业中链接社区和消费者（社区居民）的中介，社区应该建立更加方便社区企业经 营活动的服务窗口和信息平台，给社区居民提供更多样，更优质的商品和服务，同时能够让 企业提供的商品和服务能够直接在社区中面向社区居民，方便社区居民能够更加直接的接受 到产品和服务。在社区商业发展的过程中, 社区如何建立一个良好的鼓舞窗口和平台, 让产 品和服务在不增加成本的情况下面对消费者，才是社区发展的关键。

4.2.2选择信誉良好的企业合作，加强企业的宣传和管理 
社区商业的发展，离不开企业的发展。社区作为一个与普通市场有联系又有区别的商业 圈子, 怎样用商业企业的发展来推动社区商业的发展, 社区在其中扮演的角色就显得尤为重 要。社区既不能为了社区商业的发展, 对进驻的企业不加以选择; 也不能为了保证社区的稳 定性，就将所有企业拒之门外。在发展社区商业的过程中，社区应该在所有想要进驻社区的 企业中，对企业的综合状况进行评估，尤其是企业的经营能力和企业的信誉，选择经营能力 强, 发展潜力大, 信誉良好的企业进行合作。将更好的产品, 更优的服务, 提供给社区居民。 同时，社区要搭好企业和社区居民之间的桥梁，做好企业宣传的平台，让企业提供的服务和 产品能够深入到每一个社区居民心中，降低企业与社区居民之间的隔阂，以免造成因为信息 不对称，而引起的企业亏损和居民的不满。

4.2.3优化社区商业的管理，保障社区居住环境和居住安全

在社区商业发展趋势已经势不可挡的今天，不让企业进驻社区已经不可能。所以，社区 必须做好对企业的管理工作，在保证社区居住环境和社区安全程度不降低的条件下，发展社 区商业。社区必须制定相关的规定来约束企业的行为，在新企业进驻的时候，不能让企业侵 占了社区的居民住宅以及其他基础设施的区域，从源头上保护好社区的居住环境。

3.3.4 产品差异化程度低, 难以满足社区居民消费需求

社区商业的发展是伴随经济的不断发展，社区的不断壮大而发展起来的。而在一个新社 区刚刚建设的时候，难以考虑到后期社区商业发展的需求和规划造成了在后期一些企业在入 驻的时候，侵占了社区的居住区或绿化区，造成了社区的不合理布局，影响了社区居民的生 活秩序。尤其是一些比较老的社区, 在社区规划方面则更为落后, 没有意识到社区的一些规 划布局的出发点是便民和利民。造成了商业企业的进驻，不仅没有给社区居民带来更多的便 利，而是更多的不方便和正常秩序受到影响的局面。

\section{5. 结束语}

随着经济的发展，城市社区的兴起和发展，原有的社区商业已经不能满足社区居民的生 活需求。如何推动新型社区商业的发展, 以及推动旧的社区商业模式的转变成为了未来社区 商业发展工作的重点。尤其是如何处理好社区, 居民, 商业企业三者的关系, 使三者能够达 到和谐统一的发展, 更是成为了社区商业发展工作中的重中之重。企业和社区只有真正以满 足最广大社区居民的需求为根本出发点，才能真正意义上促进社区商业的发展。

\section{References}

[1] Juan Gao, Analysis of community business marketing mode based on location service, China Business \& Trade, vol.9, pp. 31-33, 2013.

[2] Songmei Zhu, The development trend of China's urban community commerce and its integration with society, Commercial Times, vo7, pp.17-19, 2013.

[3] Chen Xie, Study on the optimization path of Chinese urban community public service facilities, Smart city, vol.8, pp. 29-32, 2016. 